International Journal of

Health, Medicine and

Nursing Practice

(IJHMNP)

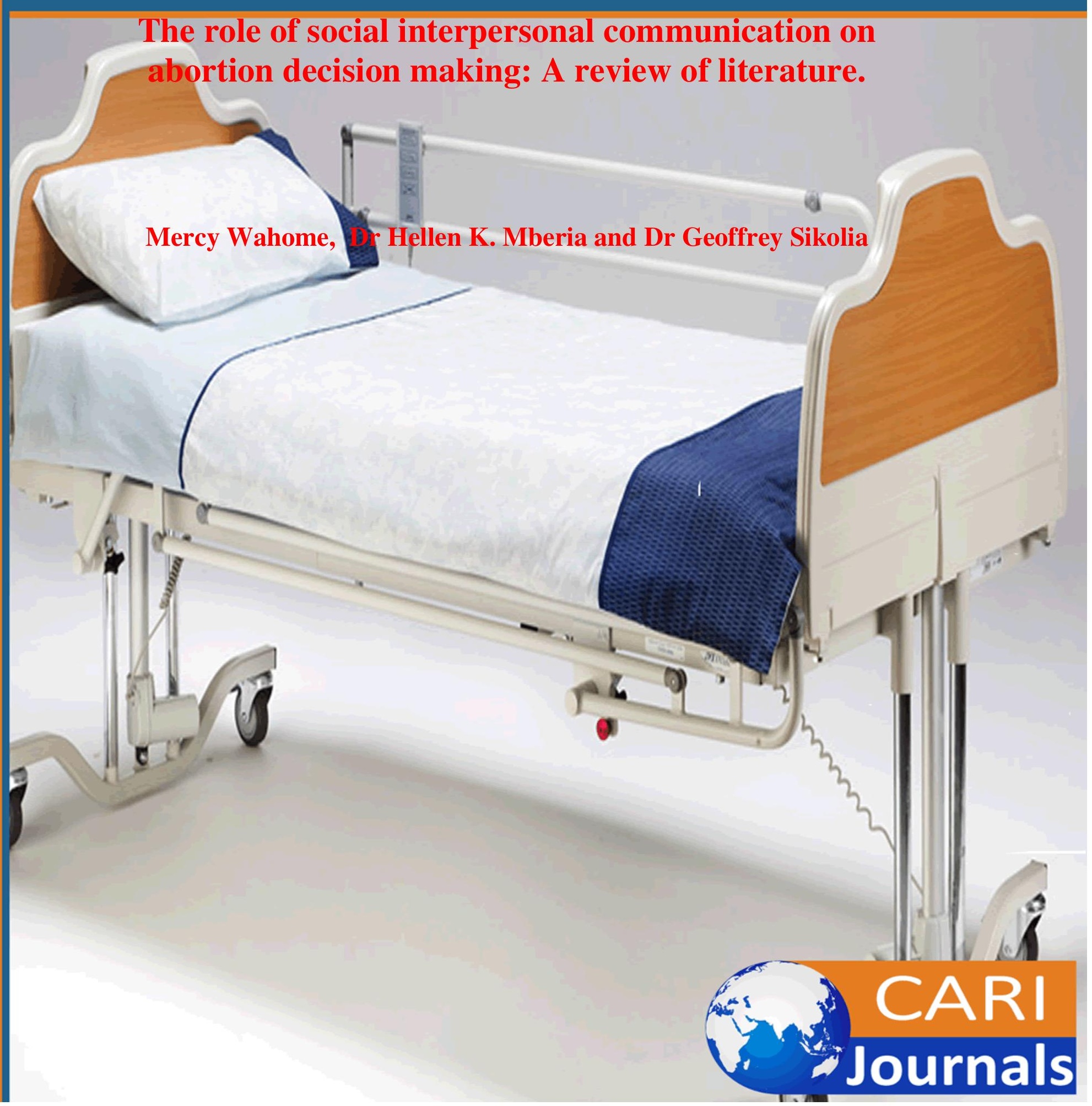


International Journal of Health, Medicine and Nursing Practice

ISSN 2520-0852 (Online)

Vol.1, Issue No.1, pp 1 - 13, 2017

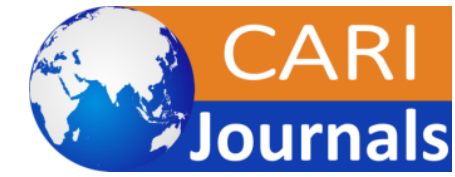

WWW.carijournals.org

\title{
The role of social interpersonal communication on abortion decision making: A review of literature.
}

\author{
${ }^{1 *}$ Mercy Wahome ${ }^{2}$ Dr Hellen K. Mberia and ${ }^{3}$ Dr Geoffrey Sikolia \\ *Post graduate student; Jomo Kenyatta University of Agriculture and Technology \\ ${ }^{2}$ Lecturer, Jomo Kenyatta University of Agriculture and Technology \\ ${ }^{3}$ Lecturer, Jomo Kenyatta University of Agriculture and Technology \\ *Corresponding Author's Email: mercywahome6@gmail.com
}

\begin{abstract}
Purpose: The objective of the study was to role of social interpersonal communication on abortion decision making.

Methodology: This study used a Desk top review. The analysis was largely based on literature review from previous surveys, program reports and internet search on secondary information relating to the social, interpersonal and communication.

Results: From the reviewed literature, the study found out that sexual health education can help provide adolescents with decision-making information skills and Peer-reviewed programs, strategies, and resources for sexual health, mental and emotional health, injury prevention, tobacco and substance abuse, and exercise and healthy eating and issues of abortion. It was found out that programs which included knowledge, perceived risks, values, attitudes, perceived norms, and selfefficacy were found to be effective in guiding behavioural change. Adolescents showed that they are aware of the use of contraceptives but they are not easily accessible and the main reason for them to terminate the unwanted pregnancy was due to fear of rejection in the society and family. Worldwide, the most commonly reported reason women cite for having an abortion is to postpone or stop childbearing. The second most common reason - socioeconomic concerns - includes disruption of education or employment; lack of support from the father; desire to provide schooling for existing children; and poverty, unemployment or inability to afford additional children. In addition, relationship problems with a husband or partner and a woman's perception that she is too young constitute other important categories of reasons. Women's characteristics are associated with their reasons for having an abortion: With few exceptions, older women and married women are the most likely to identify limiting childbearing as their main reason for abortion.
\end{abstract}

Recommendation: Since the findings of this study was based on literature review/desktop review, the study recommends for the use of semi structured questionnaires and unstructured interview guides to obtain both quantitative and qualitative data respectively. In so doing, it will enable the researcher to compare the findings with those obtained from the desk top review. This research recommends the use of Convergent Parallel research design to arrive at an integrated summary of the predictors (quantitative research), and views and personal experiences (qualitative research) on decision making on abortion.

Keywords: Social, interpersonal communication, Abortion, knowledge, perceived risks, values, attitudes and perceived norms. 
International Journal of Health, Medicine and Nursing Practice

ISSN 2520-0852 (Online)

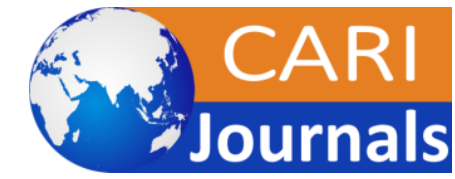

Vol.1, Issue No.1, pp 1 - 13, 2017

www.carijournals.org

\subsection{INTRODUCTION}

Interpersonal communication and social networks in Africa play an important role in influencing a woman's decision on her reproductive health status. Brems and Griffiths (1993), in their review of sessions addressing issues relating to women in development given at the 18th Annual International Health Conference, observed that ". . women's health is strongly conditioned by the political and economic environment in which they live, the society of which they are a part, and the cultural belief that organizes and gives meaning to their lives" (position paper. 257). This society and cultural belief system contain a wide range of influences, including husbands or partners, families, friends, and communities. Nyanzi, Nyanzi, and Bessie (2005) documented the significant role of men as husbands, partners, fathers, brothers, or sons in women's abortion decisions in south western Uganda and noted that interventions and policies should reflect this reality. However, these observations have been silent on the level of the women's exposure to health messages on reproductive health and abortion.

An unsafe abortion is defined as a procedure for terminating an unintended pregnancy either by individuals without the necessary skills or in an environment that does not conform to minimum medical standards or both. It leads to acute life-threatening as well as long-term disabling morbidity. World Health Organisation estimates every year approximately 4.2 million African women experience an unsafe. A new maternal mortality working group (WHO, UNICEF, UNFPA, UN Population Division, World Bank, outside technical experts) estimated that, in 2005, there were 270,500 maternal deaths in Sub-Saharan Africa (Lancet, 2007) a Region that accounts for only 17 percent of the world population and 12 percent of births worldwide. Unsafe abortion is one of the leading causes of maternal mortality and morbidity in Sub-Saharan Africa accounting for over 20 percent of maternal deaths. The tragic unnecessary deaths and suffering continue to occur despite available technologies that entirely prevent these deaths.

Worldwide, 25 percent of unintended pregnancies end up as 'unwanted or mistimed child births (Gipson, Jessica, Koenig, and Hindin, 2008), further highlighting that not every woman would invariably opt to undergo an abortion. More importantly, it further suggests that in addition to many 'push' factors that favor abortion, women also experience 'pull' factors that work against abortion. Regardless of whether people support abortion or not, abortion has inevitable health and social impacts and cannot be ignored as it's a practice with social ramification, a social phenomenon so prominent that it necessitates the creation of laws. Those women who choose to have an abortion have difficult decisions to make regarding the reasoning behind obtaining an abortion, the consequences of obtaining abortion, and their physical, psychological and financial ability to go through with an abortion or to live with the resulting outcomes of abortion. Abortions are described as controversial and prohibited topics in many African countries due to social, moral, cultural, religious, and political dimensions (Van Look \& Cottingham, 2002), and as a result abortion remains one of the five leading causes of maternal death (Grimes, 2003; Hord \&Wolf, 2004; World Health Organization,2004).

Although abortion remains illegal in Kenya, the wording in the Article 26 of the Constitution, remain vague and open to personal interpretation. The language of the article reads: "Abortion is not permitted, unless, in the opinion of a trained health professional, there is a need for emergency treatment, or the life or health of the mother is in danger or if permitted by any other written 
International Journal of Health, Medicine and Nursing Practice

ISSN 2520-0852 (Online)

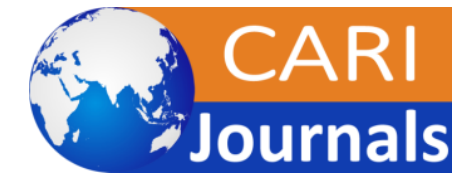

Vol.1, Issue No.1, pp 1 - 13, 2017

www.carijournals.org

law"(page 24). This vagueness has been interpreted as liberalization thus meaning abortion is legal. Despite this understanding, the fear of stigma remains real. Women are ostracized, labelled and stigmatized as killers or murderers, are perceived to be a bad influence on others, and are called prostitutes and accused of being unfaithful to their husbands or boyfriends. Younger women are perceived to be poor candidates for marriage (Heather, Sylvia, Erick, Tamara, Leah \& Sinikiwe, 2014). This demonstrates the power of interpersonal communication regardless of what the law states.

In Kenya, the Ministry of public health and sanitation prioritized increasing awareness on the importance of seeking reproductive healthcare services especially prevention of unsafe abortion. This was articulated in the Reproductive Health Communication Strategy 2010-2012. It is therefore in this background that this study seeks to investigate the interplay between interpersonal communication within families and social networks, and the exposure to health messages on prevention and dangers of unsafe abortion. The study will explore how these two affect the decision making process among women of reproductive age who have had an abortion.

The study will attempt to provide a theoretical explanation on how interpersonal communication and exposure to health messages influences the decision to undergo an abortion. Using the Theory of Planned Behaviour, the study will explore individual cognitive factors like attitudes and beliefs towards abortion that have been shaped through exposure to health messages. The theory takes cognizance of the role of subjective norm in decision making. The study will therefore explore the power of interpersonal communication within a woman's social networks when making a decision on whether to procure an abortion or not.

\section{Problem Statement}

Abortion is one of the most difficult, controversial, and painful subjects in modern society. The principal controversy revolves around the questions of who makes the decision concerning abortion, the individual or the state; under what circumstances it may be done; and who is capable of making the decision. Medical questions such as techniques of abortion are less controversial but are sometimes part of the larger debate.

The rate of abortion in the world has been significant enough to warrant investigation. "Each year worldwide, an estimated 46 million women experience an induced abortion, 36 million of whom are in the developing world" (Benson 2005; P. 189). According to calculations by Guttmacher Institute in 2008 the abortion ratio in Kenya is 21.3 abortions per 100 live births while the abortion rate is 34.3 abortions per 1,000 women of reproductive age (WRA=15- 49 years). The study by Ipas et al reported higher figures of 29.1 and 45.9 respectively. An estimated 300,000 abortions are performed in Kenya each year, and 20,000 women are admitted with abortion-related complications to public hospitals annually. This translates into a daily abortion rate of 800 procedures and the death of 2,600 women every year.

The Kenyan constitution states that abortion is illegal. A Synovate poll showed that 69 percent of Kenyan citizens were against legalization of abortion while only $9 \%$ were for it. Despite the illegality research continues to show a relatively high magnitude of unsafe abortions. On the contrary, India has relatively liberal law permitting a woman to seek an abortion to save her life, preserve her physical and mental health, for economic or social reasons, and in cases of rape or 
incest, foetal impairment, or when pregnancy results from contraceptive failure. Unfortunately, these policy and service delivery interventions have not led to a significant reduction in unsafe abortion or related maternal mortality and morbidity in India (WHO, 2010). Legalizing abortion may therefore not necessarily be the factor when one has to make a decision on whether to have an abortion or not.

According to the Population and Housing Census (2009), Religion plays a great role in guiding individuals and communities in decision making. The predominant religion in Kenya is Christianity, which is adhered to by an estimated $82.6 \%$ of the total population. Islam is the second largest religion in Kenya, practiced by about $11.1 \%$ of the total population. In these two, abortion is not permitted. Studies done in Kenya on abortion have mainly been from a biomedical perspective, focusing on effects of unsafe abortion. Other studies have looked at the psychological effects of abortion. Little is known on the communication dynamics that take place when one finds themselves in a pregnancy crises and how they arrive at the decision to either keep the pregnancy or procure an abortion, despite the health danger involved, legal implications nor the social and religious repercussions involved.

A study by Osur et al. (2015) is the most recent study that has made an attempt to understand the social networks and Decision Making for Clandestine Unsafe Abortions in Kenya. The study found that 95 percent of women consulted their social networks as part of decision making before aborting clandestinely and unsafely. The man responsible for pregnancy, friend of same sex and woman's mother were the most consulted at 64 percent, 32 percent and 23 percent respectively. 92 percent of advice was for the woman to abort. The man responsible for pregnancy and the woman's mother were the most influential advisors $(\mathrm{p}<0.05)$. Intermediaries linked the woman to clandestine and unsafe abortion and included agents and previous clients of clandestine abortion providers and the woman's friends and relatives. This study therefore concluded that decision making and seeking for clandestine abortion were shared responsibilities (Osur, 2015). However, the study does not explain the interpersonal communication that takes place between the pregnant woman/girl and the partner or persons referring for abortion, and therefore assumes a one way communication. The study did not explore the level of prior exposure on health messages on abortion thus assuming only one source of information; that of the social network. The research fails to provide a theoretical explanation to the phenomena.

The study also sought to establish how social interpersonal communication at the community interferes with one's decisions in case of an unplanned pregnancy. The findings from this study will contribute in filling both policy and program gaps in strategic communication in reproductive health.

\subsection{Research Objective}

To determine the relationship between the level of social interpersonal communication and pattern of decision making on abortion among women of reproductive age. 
International Journal of Health, Medicine and Nursing Practice

ISSN 2520-0852 (Online)

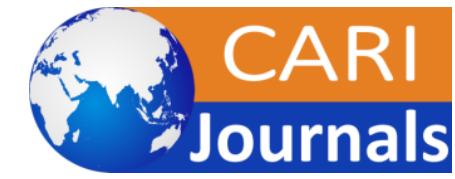

Vol.1, Issue No.1, pp 1 - 13, 2017

\section{LITERATURE REVIEW}

\subsection{Theoretical Framework: Theory of Planned Behaviour}

The Theory of Planned Behavior (TPB) started as the Theory of Reasoned Action in 1980 to predict an individual's intention to engage in a behavior at a specific time and place. It is a social cognitive theory that enables mapping of the process by which individuals form intentions to carry out future behaviour that are consistent with their self-determined motives. The TPB is a model based on beliefs that assume that an individual's intention to carry out behaviour is a key determinant for the carrying out of that behaviour (Ajzen \& Madden, 1986). Intention is a motivational construct that reflects the extent to which the individual will plan and develop efforts in order to get to carry out the behaviour (Ajzen \& Fishbein, 1980). Intention is determined by three conceptually distinct variables: attitudes towards the behaviour, subjective norms, and perceived behavioural control (PBC; Ajzen, 1991). Attitudes reflect an overall positive or negative evaluation of the behaviour. Subjective norms reflect the perceived social pressure that individuals may feel to carry out or not carry out the behaviour. PBC describes the perceived ease or difficulty associated with the execution of future behaviour. Finally, the TPB assumes that PBC predicts behaviour directly only when behaviour is not under complete volitional control and when the perceived control accurately reflects current behaviour (Ajzen \& Madden, 1986).

The theory has been used successfully in hundreds of different studies in the last two decades (Ajzen, 2011), one of the major strengths of the Theory of Planned Behaviour is that it is widely applicable to a variety of behaviours in different contexts, including such diverse areas as health communications. The TPB has been used successfully to predict and explain a wide range of health behaviors and intentions including smoking, drinking, health services utilization, breastfeeding, and substance use, among others. This study offers another opportunity to test the model and apply it to a new area of abortion.

\subsection{Conceptual Framework}

A conceptual framework aims to broadly define a number of key terms and concepts that can be used in identifying and debating the issues. The conceptual framework shows how variables interact in a diagram format. The conceptual framework Figure 2.1 illustrates the conceptualized relationship between the independent, intervening and dependent variables.

\section{Independent Variables}

Dependant Variable

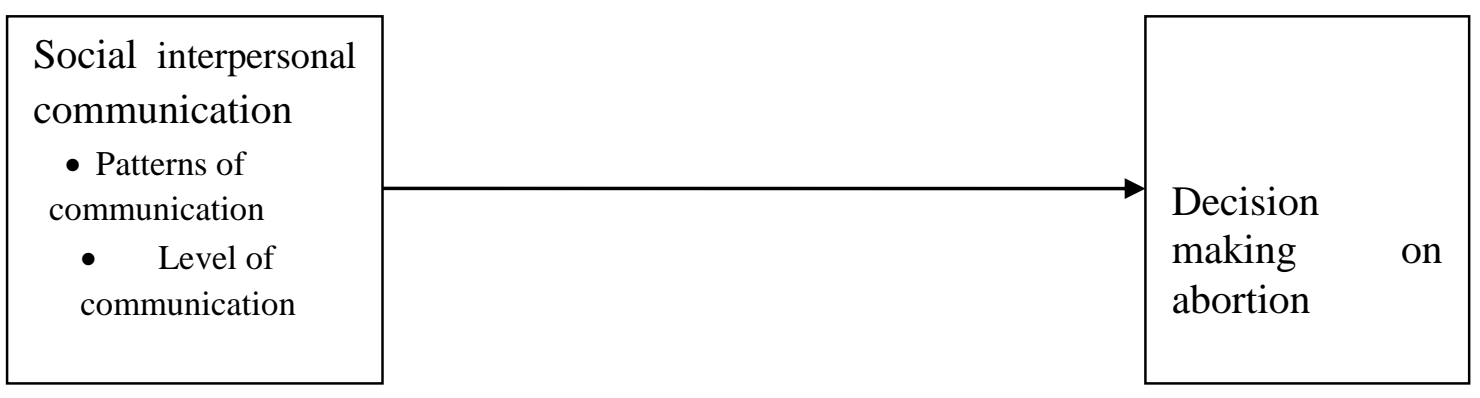

Figure 1: Conceptual Framework

Adapted from the Theory of Planned Behaviour 
International Journal of Health, Medicine and Nursing Practice

ISSN 2520-0852 (Online)

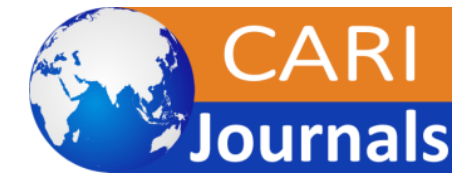

Vol.1, Issue No.1, pp 1 - 13, 2017

www.carijournals.org

\subsection{Review of the variable}

Social network analysis views social relationships in terms of nodes and ties. Nodes are the individual actors within the networks, and ties are the relationships between the actors. Examples of nodes in a social network for abortion services may be the man who caused pregnancy, the relatives that a woman confides in, the friends that provide ideas and so on. There can be many kinds of ties between the nodes, i.e. the specific contributions that a node may make in the relationship. Research in a number of academic fields has shown that social networks operate on many levels, from families up to the level of nations, and play a critical role in determining the way problems are solved, organizations are run, and the degree to which individuals succeed in achieving their goals (Scott, 1992)

Puri et al. (2007) constructed detailed case histories of 30 young married Nepali women and men. They found that decisions around unintended pregnancy and abortion are dynamic and situation specific, and that the role of husbands, health service providers, and others varies depending on the situation. In recognition of these needs, health communications campaigns are increasingly implementing interpersonal communication (IPC) approaches. Noteworthy among these are interventions and community-engagement processes based on dialogue defined as an iterative turntaking process in which each participant seeks to clarify what others believe and understand as well as one's own beliefs and understanding that focuses on interpersonal context, including family relationships and social support networks as entry points for social change.

An unwanted pregnancy causes an internal distress with the fear of rejection from parents as well as the social stigmatism that goes with being a teenager and pregnant (Engelbrecht, 2005). There is also the social dilemma's that face society in terms of normative behavior of having a child out of wedlock. The teenager may also want to seek the quickest and easiest way out of the crisis without perceiving the possible consequences because of the nature of the crisis (Hyam, 2002).

According to a study by Colman (2009), minors nearing the age of 18 years delayed their abortions till they crossed over to adulthood in order not to involve their parents in decision making for abortion which is a legal requirement in Texas where the study was done. The law in Texas requires parents to give consent for the minor to have abortion. The study suggests that minors would rather not involve their parents in decision making to have abortion. In another study done in the Netherlands (Loeber, 2008), it was found that the commonest reason why women decided to have abortion was because of relationship problems. An uncooperative man pushed the woman into opting for abortion. The study suggests that if close social contacts (spouse, boyfriend) are not pleased with the pregnancy or the relationship a decision for abortion may be made.

A dialogue-based IPC process can help to fill the void that exists in current efforts to reduce unsafe abortions at the community level in two important ways. Interventions that emphasize dialoguebased IPC are particularly suited for promoting openness and discussion about sensitive, stigmatizing, or exposing topics among families, couples, and peer networks in order to ensure good health outcomes (Duggan, 2006; Valente \& Fosados, 2006). Duggan found that silence or avoidance reduces the ability of people to receive the necessary social support that would enable them to cope with health problems, access appropriate care, and make health-related decisions. IPC interventions help participants break through this silence and improve their ability to discuss 
International Journal of Health, Medicine and Nursing Practice

ISSN 2520-0852 (Online)

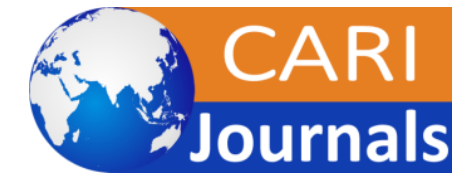

Vol.1, Issue No.1, pp 1 - 13, 2017

www.carijournals.org

these sensitive health issues with others through dilemma based role playing, dialogue, and communication skills building.

Medical workers have also been found to be important contacts in decision making for abortion. Kumar et al. (2004) found that women intending to do abortion sometimes went to health workers for reassurance. The counselling done at health facility level, however, did not make women already decided on having abortion change their minds. Contact with health workers as part of the decision making process therefore seemed to be aimed at getting more information on abortion (Kumar, 2004).

Social and cultural barriers to safe abortion go beyond lack of knowledge, however, and include lack of social support and stigma. A study in Nepal found that even when women were aware of safe abortion services, they did not reveal unintended pregnancies to their husbands, families, or friends, and some tried to secretly self-induce abortion (Puri, Ingham, \& Matthews, 2007). In families and among couples, many sexual and reproductive health topics, including abortion, can be highly stigmatized and charged with emotion, shame, and fear (Kumar, Hessini, \& Mitchell, 2009). For example, Nepali women have historically had little decision-making power regarding their lives and health; instead, decisions about their reproductive health and use of family planning rest mainly with husbands and in-laws. Pressure for early marriage and childbearing is strong. Women are traditionally unable to discuss sexual and reproductive health issues openly with their husbands or in-laws. Therefore, to make abortion safer and more accessible for women, initiatives that continues to challenge the status quo and patriarchal traditions that keep abortion restricted and stigmatized are critical (Kumar et al., 2009).

Brems and Griffiths (1993), in their review of sessions addressing issues relating to women in development given at the 18th Annual International Health Conference, observed that "....women's health is strongly conditioned by the political and economic environment in which they live, the society of which they are a part, and the cultural belief that organizes and gives meaning to their lives" (pp. 257). This society and cultural belief system contain a wide range of influences, including husbands or partners, families, friends, and communities. Nyanzi, and Bessie (2005) documented the significant role of men as husbands, partners, fathers, brothers, or sons in women's abortion decisions in South Western Uganda and noted that interventions and policies should reflect this reality.

Social networks include the extended family, friends, neighbours, political groups, church group, youth groups, and other formal and informal associations. For many women, informal communication is a primary source of FP information. Gayen and Raeside (2010) found that the informal social networks of women are important on contraception use. They further found out that both structure and attitudinal properties of one's interpersonal networks are associated with their contraception use. The influence of social networks is crucial to informed choice. Most people seek the approval of others and modify their own behaviour to please others or to meet others' expectations. In Nigeria and other West African countries for example, some women said it was difficult for them to use FP because their relatives or friends were not using it. 
International Journal of Health, Medicine and Nursing Practice

ISSN 2520-0852 (Online)

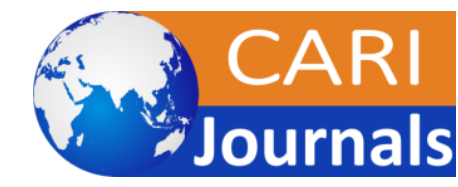

Vol.1, Issue No.1, pp 1 - 13, 2017

WWW.carijournals.org

\subsection{Empirical Review}

Rominski and Moyer (2014) conducted a study on female autonomy and reported abortion-seeking in Ghana. Variables on an individual and household level were examined by both bivariate analyses and multivariate logistic regression. A five-point autonomy scale was created to explore the role of female autonomy in reported abortion-seeking behaviour. Of the 4916 women included in the 2008 Ghana DHS, 791 (16.1\%) reported having terminated a pregnancy. Factors associated with abortion-seeking included being older, having attended school, and living in an urban versus a rural area. When entered into a logistic regression model with demographic control variables, every step up the autonomy scale (i.e. increasing autonomy) was associated with a $14.0 \%$ increased likelihood of reporting the termination of a pregnancy.

Kamala and Aboud (2006), did a study on the reasons for abortions among the adolescent in Kenya. The study examined 3,612 adolescents aged 12 to 25 years, randomly drawn from three types of secondary schools in Nairobi: single-gender, co-educational and both boarding and day secondary schools. It was found that these students have engaged in unsafe sex and some have undergone abortion due to lack of access of knowledge. The study came to conclusion that decision favouring abortion was predominantly based on their economic instability and poor support given by partners, whereas a decision against it was based on ethical considerations over its legal implications. Reliance on non-medical sources of information such as immediate associates leading to poor knowledge as well as positive attitudes on its safety played a crucial role in the decision making process towards an unsafe abortion. Unsafe methods of termination used have not changed over time.

Ayopo (2009) did a study of decision to terminate unwanted pregnancies in Nigerian adolescent students' and their attitudes towards methods prevention methods. The results were that the adolescents showed that they are aware of the use of contraceptives but they are not easily accessible and the main reason for them to terminate the unwanted pregnancy was due to fear of rejection in the society and family.

In Nepal, various factors affecting abortion decision-making have been reported. A study among 412 women (aged 15-24 years) and 125 men (aged 15-27 years) in five districts of Nepal who had unintended pregnancies reported various factors that influenced their abortion decision making process (Puri, et al., 2007). People who lived in the rural areas (Male - 12.7\%, Female - 6.1\%) had a higher incidence of abortion than people from the urban areas (Male -2.2\%, Female - 7.2\%). In general, people with higher levels of education had significantly greater prevalence of abortion compared to people with no education $(15.5 \%)$, primary $(10.5 \%)$, secondary $(11.9 \%)$, or higher (32.4\%) education. Participants from Hinduism responded with higher abortion rates $(15.8 \%)$ than Buddhism (0.0\%). Both poor and rich people were involved in abortion with significant abortion rates among poor people. Other factors affecting decision-making were ethnicity and exposure to mass media (Puri, et al., 2007). When it comes to abortion decision making, woman tend to consult with her husband, mother, mother-in-law, family relatives, friends and the abortion care providers. However, various reproductive health advocates have been encouraging and emphasizing the allowance of women to use their reproductive health rights in making their own informed decision. Family planning and abortion services among young couples have been much emphasized recently (Puri et al., 2007). 
International Journal of Health, Medicine and Nursing Practice

ISSN 2520-0852 (Online)

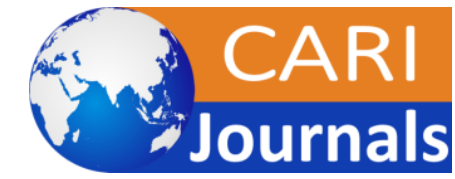

Vol.1, Issue No.1, pp 1 - 13, 2017

www.carijournals.org

A study was conducted by Akinrinola, Susheela and Taylor (1998) on the reasons why women have induced abortion. Findings from 32 studies in 27 countries were used to examine the reasons that women give for having an abortion, regional patterns in these reasons and the relationship between such reasons and women's social and demographic characteristics. The data come from a range of sources, including nationally representative surveys, official government statistics, community-based studies and hospital- or clinic-based research. Results showed that worldwide, the most commonly reported reason women cite for having an abortion is to postpone or stop childbearing. The second most common reason - socioeconomic concerns - includes disruption of education or employment; lack of support from the father; desire to provide schooling for existing children; and poverty, unemployment or inability to afford additional children. In addition, relationship problems with a husband or partner and a woman's perception that she is too young constitute other important categories of reasons. Women's characteristics are associated with their reasons for having an abortion: With few exceptions, older women and married women are the most likely to identify limiting childbearing as their main reason for abortion.

Grimes and Benson (2006) did a study on assessed circumstances that surrounded a woman's decision to undergo an unsafe abortion, compared to a decision to continue, when faced with an unintended pregnancy in Sri Lanka. The study examined 171 women admitted to nine hospitals in eight districts following an unsafe abortion (Cases) and 600 women admitted to the same hospitals for delivery of an unintended term pregnancy (Controls). Interviewer-administered-questionnaires and in-depth interviews assessed women's characteristics, decision making process and underlying reasons for their decision. The findings of his study was women's risk of unsafe abortion was associated with unreliable sources of information during decision making that led to poor knowledge and positive attitudes on its safety; poor access to affordable abortion services; and their economic instability.

\subsection{RESEARCH GAPS}

Study done by Osur et al., (2015) made an attempt to understand the social networks and Decision Making for Clandestine Unsafe Abortions in Kenya. The study found that $95 \%$ of women consulted their social networks as part of decision making before aborting clandestinely and unsafely. The man responsible for pregnancy, friend of same sex and woman's mother were the most consulted at $64 \%, 32 \%$ and $23 \%$ respectively. $92 \%$ of advice was for the woman to abort. The man responsible for pregnancy and the woman's mother were the most influential advisors ( $\mathrm{p}$ $<0.05)$. Intermediaries linked the woman to clandestine and unsafe abortion and included agents and previous clients of clandestine abortion providers and the woman's friends and relatives. This study therefore concluded that decision making and seeking for clandestine abortion were shared responsibilities (Osur,2015). However, the study does not explain the interpersonal communication that takes place between the pregnant woman/girl and the partner or persons referring for abortion, and therefore assumes a one way communication. The research fails to provide a theoretical explanation to the phenomena and therefore this study will seek to address the interplay between social interpersonal communication and decision making on abortion among women of reproductive age in Kenya. 
International Journal of Health, Medicine and Nursing Practice

ISSN 2520-0852 (Online)

Vol.1, Issue No.1, pp 1 - 13, 2017

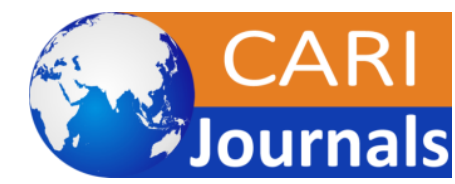

WWW.carijournals.org

\subsection{RESEARCH METHODOLOGY}

This study used a Desk top review. The analysis was largely based on literature review from previous surveys, program reports and internet search on secondary information relating to the social and interpersonal communication.

\subsection{FINDINGS}

From the reviewed literature, the study found out that sexual health education can help provide adolescents with decision-making information skills and Peer-reviewed programs, strategies, and resources for sexual health, mental and emotional health, injury prevention, tobacco and substance abuse, and exercise and healthy eating and issues of abortion. It was found out that programs which included knowledge, perceived risks, values, attitudes, perceived norms, and self-efficacy were found to be effective in guiding behavioural change.

Sex education seeks both to reduce the risks of potentially negative outcomes from sexual behaviour like unwanted or unplanned pregnancies and infection with sexually transmitted diseases, and to enhance the quality of relationships. It is also about developing people's ability to make decisions over their entire lifetime. Sex education that works, that is sex education that is effective, is sex education that contributes to this overall aim.

Kamala and Aboud (2006) found out that decision favouring abortion was predominantly based on their economic instability and poor support given by partners, whereas a decision against it was based on ethical considerations over its legal implications. Reliance on non-medical sources of information such as immediate associates leading to poor knowledge as well as positive attitudes on its safety played a crucial role in the decision making process towards an unsafe abortion. Unsafe methods of termination used have not changed over time.

Akinrinola, Susheela and Taylor (1998) found out that worldwide, the most commonly reported reason women cite for having an abortion is to postpone or stop childbearing. The second most common reason - socioeconomic concerns - includes disruption of education or employment; lack of support from the father; desire to provide schooling for existing children; and poverty, unemployment or inability to afford additional children. In addition, relationship problems with a husband or partner and a woman's perception that she is too young constitute other important categories of reasons. Women's characteristics are associated with their reasons for having an abortion: With few exceptions, older women and married women are the most likely to identify limiting childbearing as their main reason for abortion.

Grimes and Benson (2006) found out that women's risk of unsafe abortion was associated with unreliable sources of information during decision making that led to poor knowledge and positive attitudes on its safety; poor access to affordable abortion services; and their economic instability. 
International Journal of Health, Medicine and Nursing Practice

ISSN 2520-0852 (Online)

Vol.1, Issue No.1, pp 1 - 13, 2017

\subsection{CONCLUSIONS AND RECOMMENDATIONS}

\subsection{Conclusions}

Based on the findings above the study concluded that reliance on non-medical sources of information such as immediate associates leads to poor knowledge as well as positive attitudes on its safety played a crucial role in the decision making process towards an unsafe abortion.

Education campaigns have been used as a major thrust of efforts to reduce risky sexual behaviour. Education efforts assume that increased knowledge about the risks will eventually translate into reductions in risky sexual behaviour.

The study concluded that order to improve contraceptive use by adolescents, awareness campaigns, pamphlets and education should be used to inform adolescents about the availability of all methods of contraception.

\subsection{Recommendations}

Since the findings of this study was based on literature review/desktop review, the study recommends for the use of semi structured questionnaires and unstructured interview guides to obtain both quantitative and qualitative data respectively. In so doing, it will enable the researcher to compare the findings with those obtained from the desk top review.

This research recommends the use of Convergent Parallel research design to arrive at an integrated summary of the predictors (quantitative research), and views and personal experiences (qualitative research) on decision making on abortion. The same study can be conducted using health messages and demographic factors as independent variables. Further, the same study can be conducted in a specific geographical area for example Nakuru County so that the findings that will be obtained can be used for comparison purposes with the findings of the current desktop study.

\subsection{REFERENCES}

Ajzen, I. (1991). The theory of planned behaviour. Organizational Behaviour and Human Decision Processes, 50, 179-211

Babbie, Earl R. (2009). The Practice of Social Research (12th Ed.). Wadsworth. pp. 436.

Correia DS, Monteiro VG, Cavalcante JC, Maia EM (2011). Female Teenager Students: What They Know About Induced Abortion Complications. Rev. Gaucha Emferm.

Duggan, A. (2006). Understanding interpersonal communication processes across health contexts: Advances in the last decade and challenges for the next decade. Journal of Health Communication, 11, 93-108. 
International Journal of Health, Medicine and Nursing Practice

ISSN 2520-0852 (Online)

Vol.1, Issue No.1, pp 1 - 13, 2017

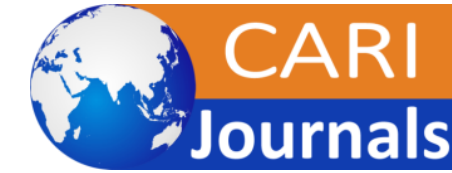

WWW.carijournals.org

Ferreira, M. (1985). Abortion and family planning: A literature study. Pretoria: Human Science Research Council.

Gipson, Jessica D., Michael A. Koenig, and Michelle J. Hindin. 2008. "The effects of uninintended pregnancy on infant, child, and parental health: A review of the literature." Studies in Family Planning 39(1): 18-38.

Heather M, Sylvia W, Erick Y. Tamara F,Leah W, Sinikiwe M 2014). Women's perceptions about abortion in their communities: perspectives from western Kenya, Reproductive Health Matters: 22(43):149-158

Njogu W, Martin TC (2003). The persisting gap between Abortion knowledge and perception among Kenyan youth. GENUS 62(2)135-168.

Nyanzi S., Nyanzi B., Bessie K. (2005).Narratives and experiences of commercial motorbike riders in south-western Uganda. African Journal of Reproductive Health. 2005;9:142161.

Puri, M., Ingham, R., \& Matthews, Z. (2007). Factors affecting abortion decisions among young couples in Nepal. Journal of Adolescent Health, 40, 535-542.

Rominski, S.D., Gupta, M., Aborigob, R., Adongo, P., Engman, C., Hodgson, A. \&Moyer, C.(2014). Female autonomy and reported abortion-seeking in Ghana, West-Africa. International Journal of Gynecology and Obstetrics; 126, 217-222. 